\title{
Modular Nuclear Testing Concept
}

\author{
L. F. Wouters
}

\begin{abstract}
DISCLAIMER
This report was prepared as an account of work sponsored by an agency of the United States Government. Neither the United States Government nor any agency thereof, nor any of their employees, makes any warranty, express or implied, or assumes any legal liability or responsibility for the accuracy, completeness, or usefulness of any information, apparatus, product, or process disclosed, or represents that its use would not infringe privately owned rights. Reference herein to any specific commercial product, process, or service by trade name, trademark, manufacturer, or otherwise does not necessarily constitute or imply its endorsement, recommendation, or favoring by the United States Government or any agency thereof. The views and opinions of authors expressed herein do not necessarily state or reflect those of the United States Government or any agency thereof.
\end{abstract}

PECEIVED

JAN $\supset 9097$

) S TI

July 14, 1964
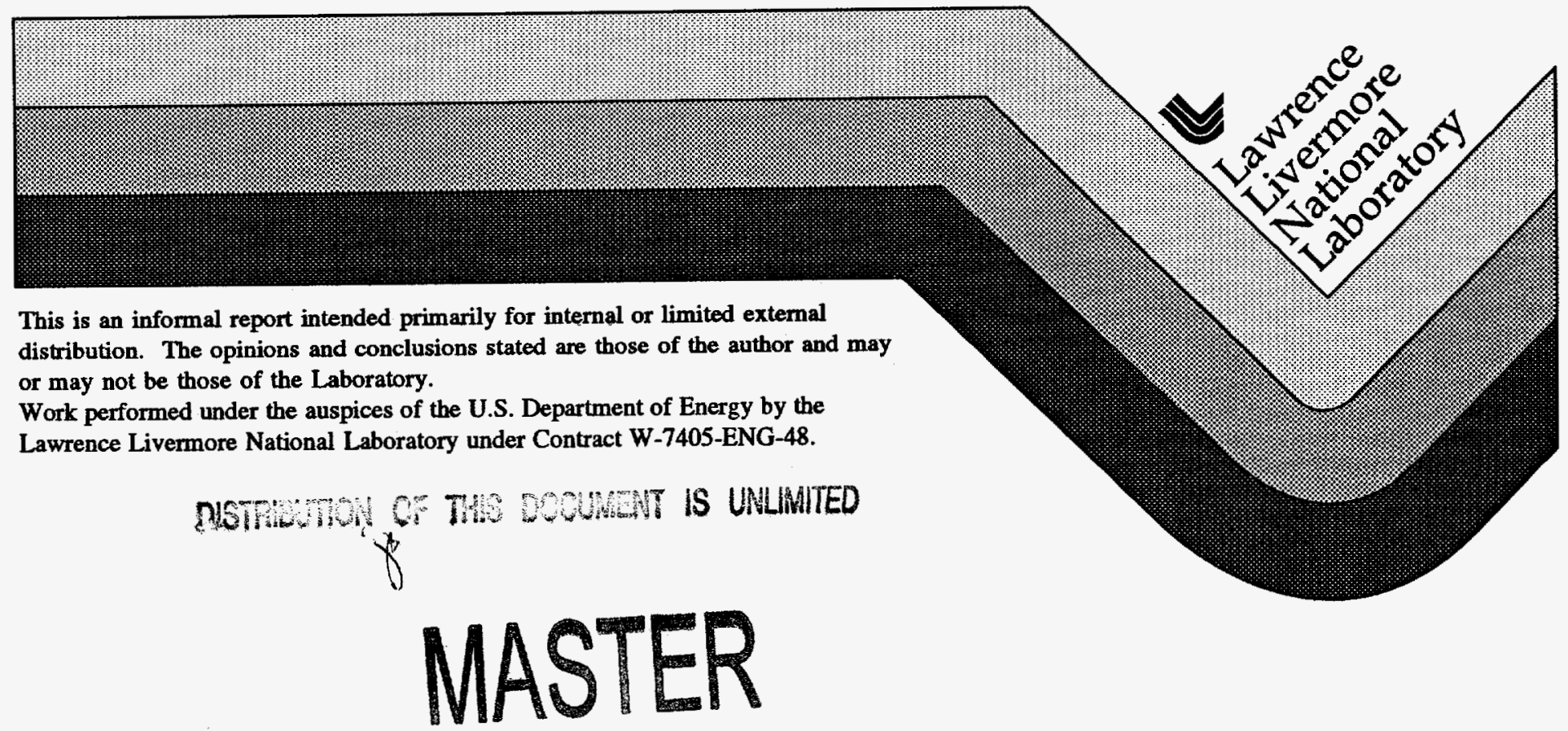


\section{DISCLAMMER}

Portions of this document may be illegible in electronic image products. Images are produced from the best available original document. 


\author{
MEMORANDUM - 14 July 1964 \\ TO: $\quad$ J. Carothers \\ FROA: $\quad$ L. F. Wouters \\ SUBJ: Nodular Nuclear Testing Concept
}

The continuing concern with efficient utilization of manpower at NTS and the seemingly high cost of individual nuclear shots, together with the recent evolution of the I-I2 scope, generated some fresh thoughts conceming more efficient procedures for the "average" test. Every time anyone looks at the problem, they tend to analyze the existing conventional approach and try to find the one or two most expensive and "lossy" factors in the can of worms. Usually this turns out to be a problem within the realm of specialization of the particular analyst! People not so directly concerned with the program tend to look for, or wish for, or even "invent", "miracles". To the extent to which I can be objective, our present techniques strike me as being the sum (and possibly even the product!) of many small contributions which have all been beaten down to the same level of importance. Such a situation in any systemic problem is usually symptomatic of the need for fairly violent departures in the over-all system approach - at least in thinking.

My own personal pipe-line into the problem at first involved consideration of the electronic diagnostic aspect (the specialist!), but it became quickly evident that the major issues were of a much different functional, organizational, and capital investment, character. (We ran into precisely the same situation in designing the readiness aircraft systems.)

Perhaps the most serious block to effective thinking about the problem, are certain traditions left over from atmospheric "bunker" days - In particular - certain basic plant limitations that exist today, because we were initially more-or-less forced to utilize equipment and methods inherited from that time. With respect to the electronic diagnostics for instance,

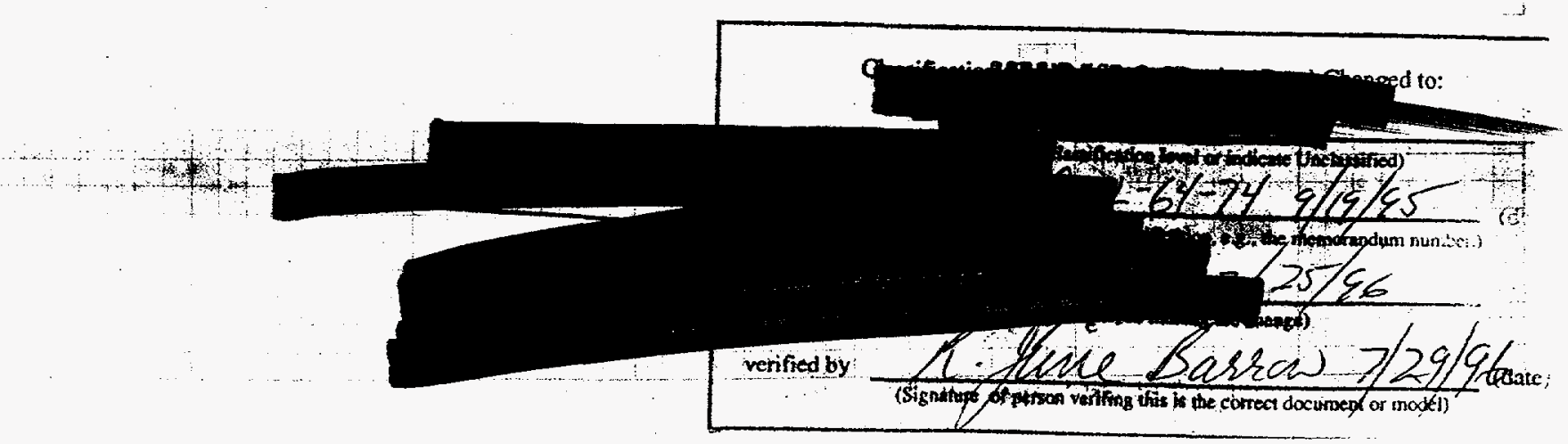


the old design restriction that almost everything intendea for bunker installation, had to be in the form of "hand carry-in" units, turns out to be a most significant limitation.

Now anproaching the problem from a functional standpojint, one of the problems that has caused much concem in recent history, and wich many of us are still unhappy about, is the "portal-to-portal " business with respect to technicians and engineers; roughly $1 / 4$ of $a$ working day is lost by the necessity of daily moving a substantial number of highly trained men from Mercury to the forward areas. This suggests that a "hew approach" should attempt to use these people at a location which would significantly reduce such "in-house" travel time (and possibly even in a location which would impose much less personal sacrifice in "getting to work".).*

The basic concept that I wish to introduce here, involves moving most of the activities carried out at the ground zero location at least to Mercury (and possibly even to Las Vegas). This would involve the creation of a security compound with appropriate permanent buildings, tooling, test equipment, etc., etc. for assembly and testing of diagnostic canisters, device canisters and prompt diagnostic trailers. Essentially, I am proposing that all internal system installation, testing and setting-up, be accomplished at the central location and that at a time like mims five days the entire system be transported in suitable vehicles to the shaft location. To be really radical, I think that even the down-hole and surface cables could be transported on specially designed trucks - which would eliminate the need for in-the-field timing runs. As suggested by Jim C., the device would be mated to the system at an intermediate stop - say a new specialized working area along the highway near BIdg 10 . It is even possible that the FPFF dry-run could be closer to D-day with such an arrangement.

*It is certainly true that, seen from a "Simon Legree" viewpoint, those men are hired to be at Mercury at eight o'clock, and how they get there and how inefficient their personal time utilization may be, could be said to be none of our concern - But it is also a measure of progressive modern management that consideration is taken of the consequences of off-hour behavior and involvements, as it affects working efflclency and effectiveness. (To the extent that management chtrols, moonilghting", detrimental activities, fete.

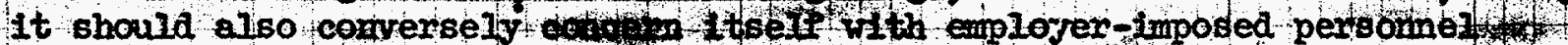
penaities.) 


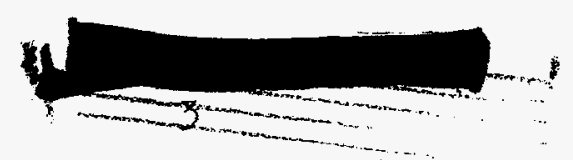

The Trailer Package

My original approach to the problen resulted from the realization that if one could put four traces into an $i,-12$, one can put eight traces into an "L-123" - and furthermore, the $L-123$ could represent essentially a single chain in a line diagram. The $1-123$ would be a multi-trace unit capable of recording the output of a single detector and inclucing all of the creep and dot rossis, markers, triggers, etc., normally associated with one detector. This would be a big chassis, but this is only a problem if one insists upon medieval handling techniques. To be sure, we would have to design specific L-123 units for various functions - for instance, there would have to be an I-123 model for photomultipliers, one for photodiodes, and one for compton diodes. There would need to be alpha-measuring versions, and also time-interval measuring units (using photodiodes and Compton diode inputs with slower dot rossis, etc.) and cross-timing units. Each L-123 unit would have a power input, a signal input, an X-unit trigger input, a cross-timing output, and possibly a signal tap-off to permit insertion of isolated scopes and special timing and calibration pulses. (Maybe also a "sync" input.)

My confidence in suggesting a scheme of this sort stems from the point of view that not much has changed really, in our desiga of alpha and interval timing line diagrams in the past years; one can find more-or-less average designs from thich most line diagrams represent only small departures. To be sure, there are continuing argments between the "lor-Rossi", and the "high-Rossi", contenders, but when you look at the results, it really doesn't make that much difference. I think one should impose inflexibility where experience has shown that flexibility really doesn't gain mach (like $80 \%$ of the cases) - simply on the grounds that this may allow. considerable economies, and permit more attention and effort on other kinds of capabilities and problems, if one uses a little imagination.

How soon could such a scheme be tried? If the units have to be designed from scratch, one will obtain all kinds of estimates, from six months to 18 months, which is like killing the idea. As Jim C. has also suggested, we cculd generate some sort of immediate prototype test by, in effect, "welding" a number of our present units into a single inflexible package. Such a package would incinde guite a variety of buiky yats, such ds trigger/mar generators, power supplies, $33^{\prime} 43^{\prime} \mathrm{s}, 517^{\prime} \mathrm{s}, 507^{\prime} \mathrm{s}, 3445^{\prime} \mathrm{s}$, etc., etc. - In fact it would amount to just about one standard rack per detector. 


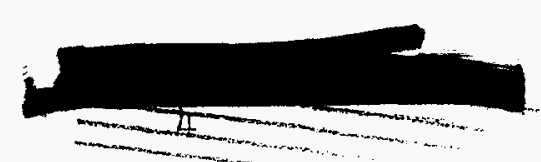

$\cot 64-74$

Assuming that we zero-in on that basic number of one rack per detector, and that a Iine diagram now consists of a specification of $\mathrm{L}-123$ racks and switch positions (that's a concession:), we now finally come to grips with the assembly, installation and servicing problems. At this point I like to tell the story bout color IV sets. These are relatively big, cumbersome pieces of electronics and they are still not all that is to be aesired in terms of reliability and longevity, but just the same the industry and trade has quite a line of effective handling tools that permit the service man to cope with this basically tractable device. For instance, in servicing the units, they are not placed on a service bench, but are placed in a Gimble-mounted frame that rotationally permits convenient access to any point on the chassis in a three-dimensional sense. Handling is essentially an engineering problem and should be treated as such.

So I have come up with the following thought: the diagnostic trailer now becomes essentially a frame work for holding I-123 units. One side consists essentially of vertical stanchions between each unit; the I-I23 units are permanently attached to cover plates that form that side when the installation is complete. They would be picked up at the servicing and installation area by means of a suitably equipped "fork truck", inserted into the side of the trailer and bolted in place. One end of s. laid in troughs above the scope unit bays. Power and other special muns (such as camera operation lines) would be laid in a false floor underneath the scope units. Such a design completely prohibits access to the units and dictates that if the unit fails in a manner not amenable to "screw holes and knobs", one palls the unit and replaces it with a fresh one from Mercury. I realize that such an arrangement makes fantastic demands on reliability and stability - but if we are going to make any progress in any direction that's a necessary upgrading anyway, in the next few years. The question of access to the front panel really becomes almost trivial compared to present practice - it simply becomes a place to mount the cameras and take dry-run pictures.
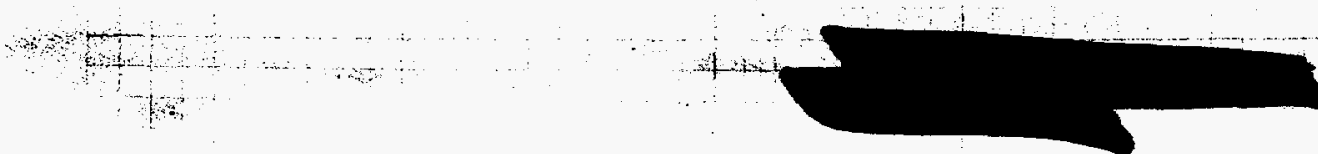

seds: 
The Canisters

While I have not given as much consideration as to how to handle the diagnostic and device canisters, I tend to feel that most of the vork that is done in fomard area shacks could just as well be done back at Mercury. Basically, these ideas are based on the concent that it is cheaper, more efficient and better practice to move equimment in large, intecra]. packages with a minimum number of men than to move lots of small units, parts, servicing equipment and lots of men to go with them.

Canister/cable mating is a fairly demanding activity in the forward area, since from these steps, basically arise the need for the various shacks - as well as for much consumption of working time by many hands and heads, most of whom are standing around most of the time. The really sensitive items are those that can potentially cause destruction and casualties The primary and the gas bottIes. So I suggest that, for most shots, these units be installed through access ports at the "BIdg 10 " stop. For preparational dry-run purposes, one uses dumby primaries, having identical electrical characteristics, and inert gas bottles (as at present). (The question of moving a completely assembled down-hole system, with live device, across Yucca flat isn't so bad - one does this at 2 A.M. after completely closing the highwy 6 After all, we $12 y$ B 52 hs with stockpile devices over our heads all the time!)

It would certainly be awkward to transport the system in its normal vertical position. So a special handling truck, similar to MRBM transporters would need to be devised - And the weapons people will simply have to supply devices that can be rotated $90^{\circ}$ without falling apart!

$I$ FW $/ O C$

1A. J. E. Carothers

2A. J. N. Shearer

3A. File

4A. Bile
Series B: $7 / 31 / 64$

$1 B$ A. Goeckermann

$2 B$ A. Hyne

3B V. Denton

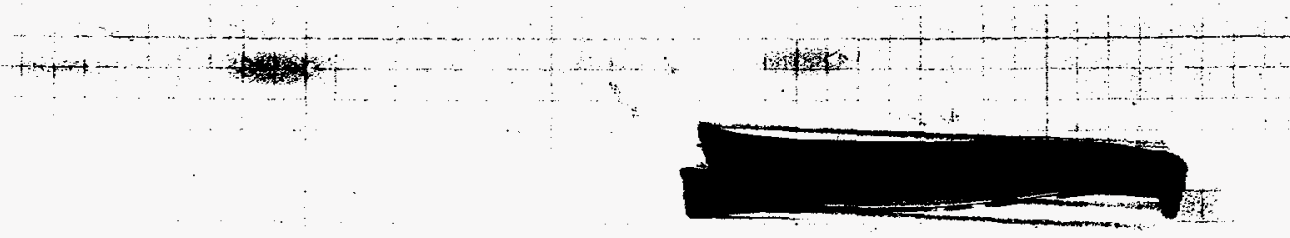

